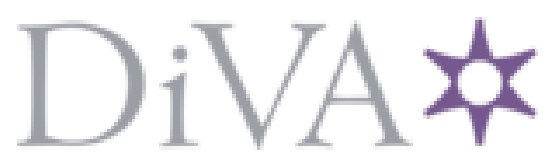

http://www.diva-portal.org

This is the published version of a paper presented at ITHET 2014-13th International Conference on Information Technology Based Higher Education and Training, York, United Kingdom, September 8-13, 2014.

Citation for the original published paper:

Svane, T. (2014)

Reality Mining in the Classroom: Simulating social behavior from machine-sensed environmental data.

In:

N.B. When citing this work, cite the original published paper.

Permanent link to this version:

http://urn.kb.se/resolve?urn=urn:nbn:se:hh:diva-27336 


\title{
Reality Mining in the Classroom
}

\author{
Simulating social behavior from machine-sensed environmental data
}

\author{
Torben E. Svane \\ School of Information Science, Computer and Electrical Engineering \\ Halmstad University \\ Halmstad, Sweden \\ torben.svane@hh.se
}

\begin{abstract}
This paper presents three simple applications to let students work with data generated from their mobile phones. The applications can be used as demonstrations for courses in e.g. data mining, business intelligence, and development of digital and web services. One application is entirely web based, the other two require a technology investment of about 200 USD, but the devices may also be an asset for other research/demonstration purposes.
\end{abstract}

Keywords-teaching; data mining, business intelligence, reality mining, big data, simulations, interfaces, SMILE, IT privacy.

\section{INTRODUCTION}

For some years, Reality Mining (RM) has brought new ideas to Business Intelligence and Data Mining. Analyzing personal data from mobile phones and other user devices was considered one of the breakthrough ideas for 2006 [1]. Introduced that same year [2], the RM concept targets e.g. information access, social relations and user group ("tribe") behavior [3], and builds upon Big Data [4], [5] - large amounts of data generated from individuals and their devices. It is difficult to find such data for a classroom setting, so we have let students themselves actively take part in the data generation. This paper presents three simple applications where students work with data generated from their mobile phones. Two are student developed Android apps (a location-based game and a simulation of customer flows in a shopping mall) and the third is an online simulation of customer flows in a fictional shopping mall through reading QR [6] codes. The technology requirements for demonstrating the Android app will in most cases be less than 200 USD. The online simulation only requires that students have a $\mathrm{QR}$ code reader in their mobile phone (which can be downloaded for free for all major mobile device operating systems). The applications may also be useful in discussions on new types of user interaction, e.g. from a presentation of the SMILE [7] acronym for interfaces or in discussions which highlight legal and ethical concerns in gathering data, as well as IT privacy [8], [9], [10].

\section{COLLECTING DATA}

As we move around in our environment, "smart" mobile devices (most often, mobile phones) both collect and transmit location and other data so that we can use the many services available which build upon where we are, what we do and sometimes even who we are. While many users deliberately turn on the distribution of device data (so that they may gain access to services embedded in their environment) there are also studies [11], [12] which report on more general user privacy concerns and difficulties users may experience when trying to configure their privacy settings. Hence, many mobile phones are open for collection of data as their owners carry them around - but perhaps without the user's full insight about what data is sent.

Data collection from mobile devices - and where the collection does not require an explicit consent from the carrier/individual - is often named "unobtrusive" [13]. Typical applications may include visitor flow analysis in shopping malls [14], [15], [16] or location services to help a visitor find places [17], [18]. Even though perhaps both useful (to shopping mall management) and helpful (to end users) there are great concerns in governments about the legitimacy and appropriateness in privacy intrusions [19]. So far however, vendors still market their solutions with arguments claiming the equipment only tracks devices and not humans - which of course may be technically correct. In their selling points however, most analytics refer to mapping out "visitors" or "shoppers". Although highly relevant and a given topic in class discussions, legal issues, IT ethics and similar aspects will not be discussed in depth in this paper.

Because of the need for fairly accurate location data, indoor sensing systems seem most common [20], [21]. In our own projects with device-sensing units, the triangulation (locating the device) kept accuracy within a couple of meters with receivers set up in a triangle with approximately 15 meter sides (equilateral). In most cases where the user is aware of the data collection (as in helping to find the way) the mobile phone screen is used for presentation. There are also studies reporting on other display techniques, e.g. a mobile projector to show the way via a floor display [22] or other (long-time predicted [23]) devices.

There are many approaches to collecting the required data. In a more technically oriented overview of opportunistic user context recognition [24] such different technologies as accelerometers and gyroscopes, positioning sensing through Bluetooth, cell tower signals, GPS and Wi-Fi. Ambient sensors such as cameras, microphones and magnetometers are also mentioned. In most of the reviewed studies, the connection communication (a so-called 'ping') between the mobile phone and nearby cell towers seems to be most common. Data collection may include physical location (within a few meters), time at that location (the device doesn't change coordinates), speed of movement though accelerometer or changes in location, or even location of the cellphone (in your chest, or trouser, pocket) [ibid.]. 


\section{USING DATA}

Running classes with an ERP (Enterprise Resource Planning) [25] focus will many times include coverage of Business Intelligence, Data Mining and Data Warehousing [26], [27]. Traditional course content may however have to embrace new concepts as well - or perhaps set up entire new curricula with a focus in Big Data, Business Intelligence and Analytics [28]. Our aim has not stretched that far, but the need to also include newer approaches (Big Data, Reality Mining) has been discussed for several years (and was gradually introduced from 2010).

Universities often provide student access to ERP systems and workshops may often include data mining exercises. Most data available in such systems are however business/transaction oriented, i.e. invoice, sales, and accounting data. Facing an ongoing expansion of mobile subscribers - around $120 \mathrm{M}$ new mobile subscriptions only in Q1 2014 [29] - it is likely that analyzing social (device) data from e.g. mobile phones will increase in importance. Smartphones will hence continue to transmit data to the surrounding environment - insights which are useful to have for students. As vendors also move mobility data forward [30], more possibilities will emerge and datasets will be easier to embed also in non-traditional types of exercises. A comprehensive study of ERP use (systems and methods) in German institutions [31] report that $61 \%$ of the 59 universities included (research oriented, or applied science oriented) use practical exercises as a method of teaching. In that same study, it is also reported that a mere 7\% (4 of 59) use simulation games; the same result is reported for "other teaching". As the study focuses systems and functionality there is no information about what areas the exercises and simulations target. In our courses, hands-on simulations, not necessarily in front of a computer, are encouraged. Other work [32] has also reported on positive results in terms of general ERP knowledge, learning skills and understanding when using games.

There is - and has been for a number of years [33], [34] an ongoing discussion on content in ERP classes/degrees in general and also specifically with regard to e.g. data mining [35]. Searching Summon (http://www.proquest.com/productsservices/The-Summon-Service.html, July $25^{\text {th }} 2014$ ) indicated however that Reality Mining was not common in any curricula yet. Not even a paper with specific focus on the ACM SIGKDD (Knowledge Discovery and Data Mining) base curricula [ibid.] mentioned keywords as "Business Intelligence" or "Analytics". Although changes most often will - and probably need to take time, it seems as though insights from earlier research not always find acceptance in the short (currently, 12 years) run:

...volatility and change has been the hallmark of technology, and Enterprise Resource Planning (ERP) may not be immune from such changes... [33]

It is unlikely that a topic such as Reality Mining or insights about mobile Big Data currently, and in a foreseeable future, not will be in the center of ERP education. There are however many indications [36], [37], [38] that LBS (Location-Based Services) data will both expand over time and become increasingly interesting from many perspectives. Mobile phone subscriptions are predicted to reach 9.2 billion by the end of the decade, with 5.6 billion smartphone subscriptions and $80 \%$ of mobile subscriptions (overall) able to handle broadband [29].

\section{WORK}

Our classroom coverage of Reality Mining was introduced in 2012 through lectures, presentations and discussions. The base website for VisiTracker (up until this year, our only demo for instant data collection via QR codes, fig. 6-12) was also developed at that time. In the recently ended academic year (2013-2014) the more responsive real-world, real-time mobile phone apps have been developed and tested. As the apps still are very new there have been only one classroom run but several are planned for this next-coming academic year.

Reality Mining, as we see it, can cover numerous methods and data types. The first app developed was therefore not what would be typical for use in an ERP setting but a very simple location game (ARC Defense, fig. 2-5) where two players build defense castles, and attack the opponent's buildings to win. For real-time data simultaneously distributed in both phones, we have used Firebase (www.firebase.com) for instant data feeds.

The second app (fig. 13) was a complement to the QR code web application and presents location data as they could be collected in a fictitious shopping mall (Moensterby Center). The app (currently, only for Android) is downloaded, installed and activated. The VisiTracker app then scans its mesh (the area covered by the wireless access points) and registers the MAC addresses of devices within that area which uses the app (see fig. 13 for table/map output). The units are shown in fig. 1.

\section{A. Using location data from mobile phones}

Our apps use the Navizon Indoor Triangulation System (www.navizon.com) which communicates with hardware from OpenMesh (www.open-mesh.com). The wireless access points build a detection grid, with one unit connected to the Internet. Units can be places up to 60 meters from each other. The longer the distance between is nodes, the more the location accuracy diminishes. Our tests have used a 15-30 meter range.

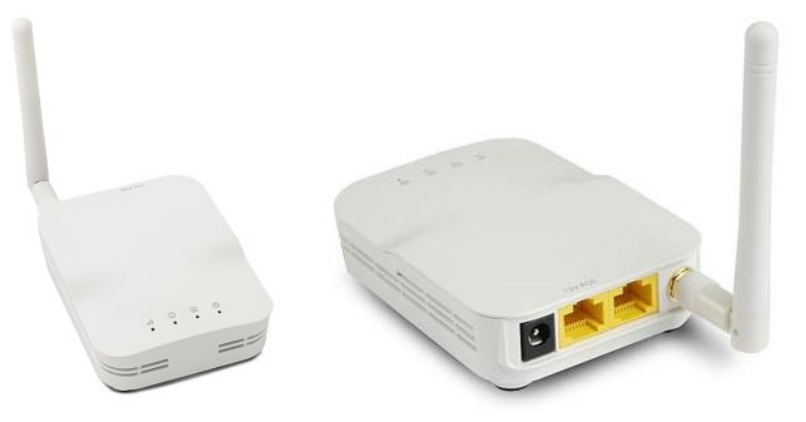

Fig. 1. The Open-Mesh OM2P Access Point (images used with permission)

ARC Defense is a battle game written in Java for Android. Two players enter, and after a few seconds their battle starts. The options are building defense towers (which take time) or attacking the opponent (vulnerable during the building phase). Once enough towers are in place, they will help healing their owner, meaning there is a tradeoff between just attacking and (more strategically) invest time - but at a risk - in defense.

The main purpose of the game is not really the gameplay but the possibility to show students how real-time, accurate location data can be collected for later, and further, analysis. 


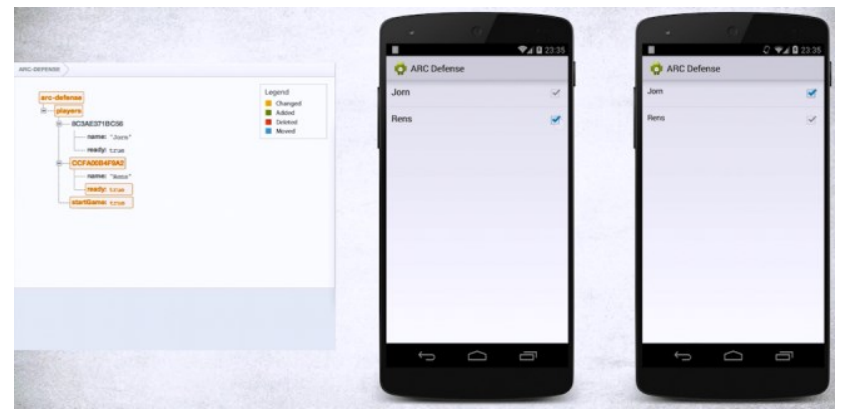

Fig. 2. The startup screens for the game. To the left is shown Firebase data.

To make the setting more realistic, Google Maps are used as a background. The common Marker icon is used to denote players, and own tower icons (red and blue, and indicating if a tower is damaged or not) are added to the map as the game is played. A compass needle is displayed in the upper left corner, and the map rotates when a player (phone) faces a new direction.


Fig. 3. Players marked on the Google Map.

Once the game is underway, more options unfold in the players' menus. If you are building a tower, you will be updated on-screen with the current construction status. Logged in to Firebase, the entire group can follow the constant update of both location changes and current values for players and structures.

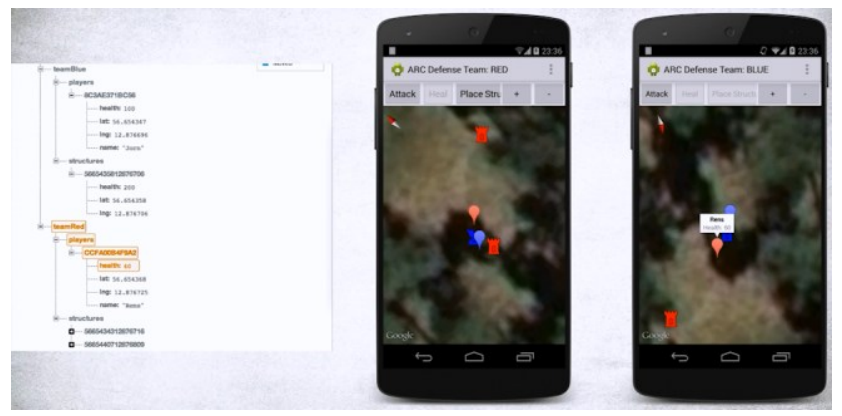

Fig. 4. Players amidst in battle. The red team is building towers.

To limit the timespan of each game there are imposed restrictions on how many towers a player can build. Games will typically only take a few minutes. Current data values are kept in Firebase (for the real-time functionality). Data is also stored in a traditional (MS SQL) database for the subsequent analysis.

Not all devices which can connect to the detecting grid (meaning they have a MAC address) can participate - a laptop will not have gyroscope and accelerometer, to mention a couple of restricting limitations. We found that mobile phones are to prefer, tablets are too big to handle with ease for the game.

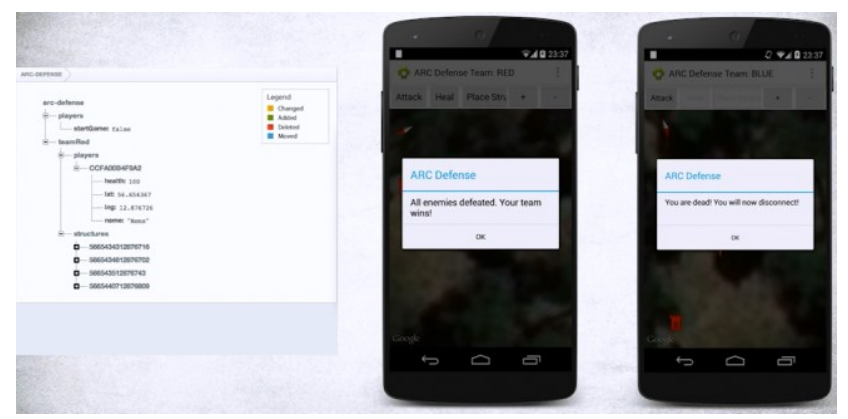

Fig. 5. This ARC Defense battle is over. The red team won.

\section{B. Simulating shopper activities via $Q R$ code entries}

Before we had access to hardware and services which made it possible to generate actual (real-time, real-location) user data we created a fictional - but as realistic as possible - shopping mall. We set up a complete concept for registering visitor data, engaging shop owners and facility management, and creating incentives (a "lottery" where each scanned code represents an entry/ticket in a later - also fictional - drawing for prizes).

The VisiTracker concept got its own website describing the concept and a "selling video" to boost the idea further. There are also around 50 personas (shop owner profiles) developed and six short videos created where the shop owners speak about the coming event (the QR code days in the shopping mall).

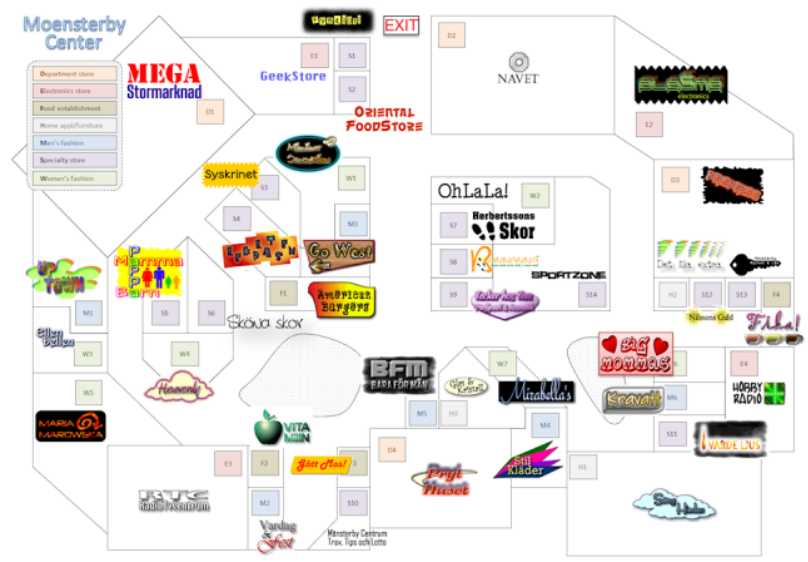

Fig. 6. The fictional Moensterby Center shopping mall.

Different from mobile apps (which are operating system dependent) mobile web pages work for any device which can access the Internet and have web browsing capabilities. To be fully functional, the unit also needs a QR code scanner/reader but there are several for any of the major operating systems and the ones that are free are, in our view, as good as paid for.

The full page flow is displayed for illustrative purposes on the next page but in short, a visitor enters the shopping mall and scans a starting QR code which enables the collection of lottery tickets as codes are scanned. When the visitor leaves the mall, an end code is scanned, and a ticket receipt is displayed. 

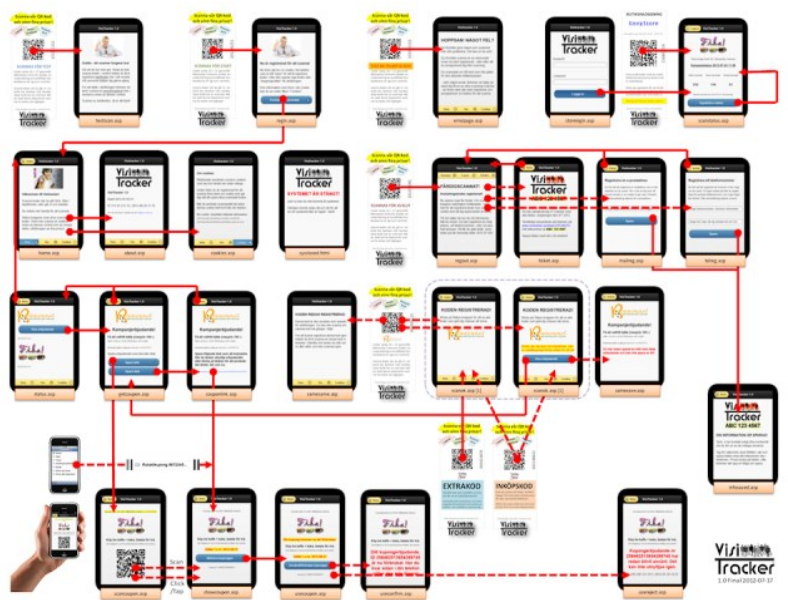

$\frac{\text { Viritem }}{\text { rockert }}$

Fig. 7. The VisiTracker page flow for the 1.0 (September 2012) release.

When the concept has been explained to the students, there is an initial discussion on what data will be collected, under what circumstances, and the potential use(s) of registered data.

At this stage there is not so much discussion about ethics or IT privacy as all our applications require affirmative consent from the user. The discussion seems to instantly trigger when examples of unobtrusive (and commercial) systems are presented. Initially however, we try to keep all focus on our exercise.

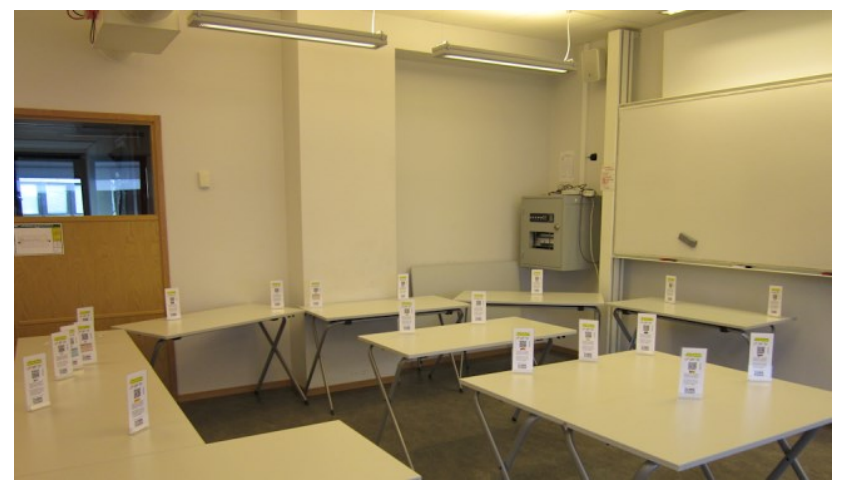

Fig. 8. The left half of the center as it is set up in a classroom. GeekStore and Oriental Foodstore (see fig. 6) are by the whiteboard, with MEGA in the corner.

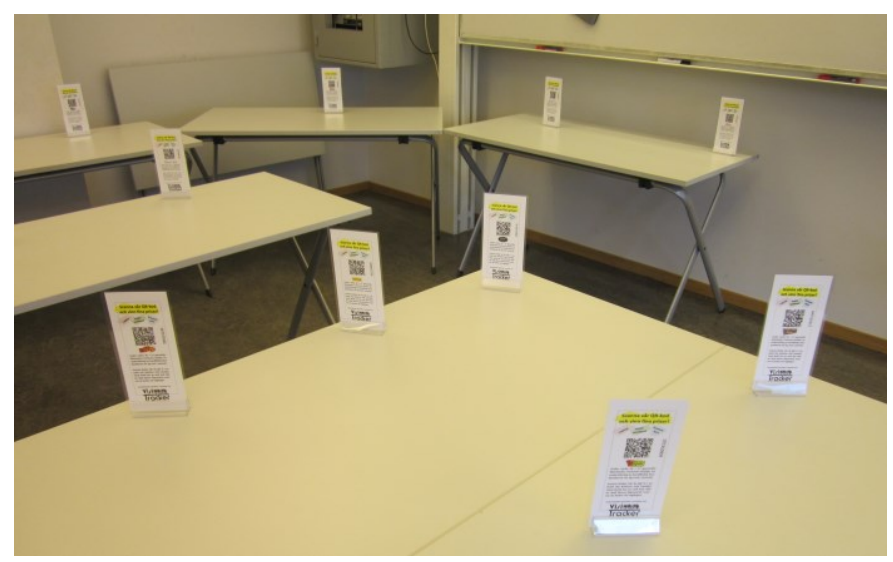

Fig. 9. All signs are marked with store logos (all brand names are fictituous) and a unique QR code which will register an activity by a visitor in that store.
To add more variation to data, it was also made possible for stores to have additional codes, e.g. when a customer bought something (the orange label) or for other activities which they would like to have measured during the event (blue labels).

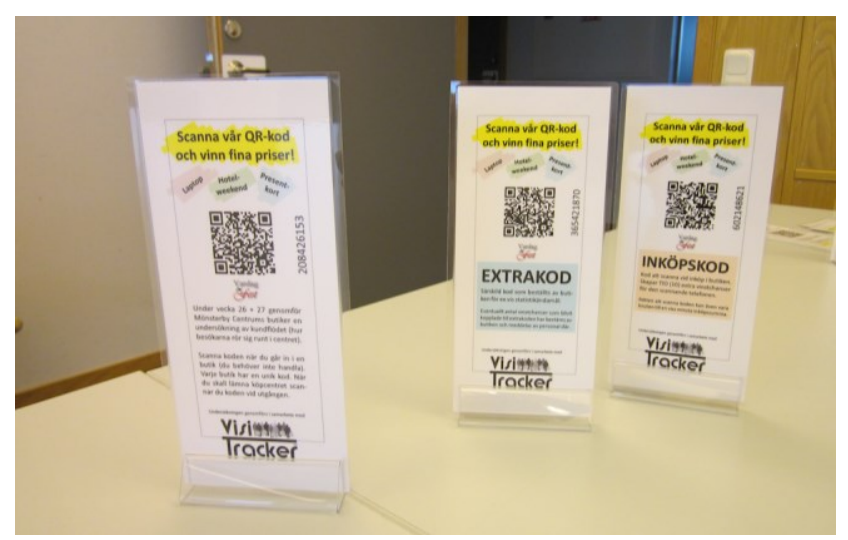

Fig. 10. QR code stickers for visiting, extra activities, and actual purchases.

Although carried out in a very unrealistic environment (a classroom, rather than in a real shopping mall), most students engage in the gameplay and even discussed different dresses in a women's fashion store. As the space is rather small compared to a real shopping mall, many codes will be scanned at short intervals, making e.g. flow data impossible. Moving from one store to the next is done in seconds (being only a couple of steps).

From data generated (this is of course not the Big Data volumes which would be the case in a real situation) students can investigate e.g. how many visitors from store $A$ that went to store B for their next stop. Although very simple as a point of analysis, it has brought up discussions on customer behavior.

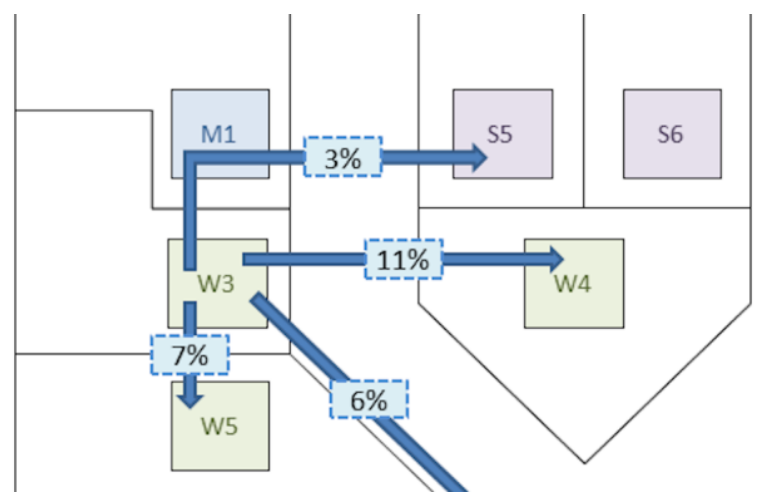

Fig. 11. A simple analysis of customer flows after leaving a store.

To get larger data sets which can be used more meaningful in professional software as QlikView ${ }^{\circledR}$, we have developed a simple visitor data generator (MallSim) which can have up to 1000 "visitors" go through the mall and register data with more realistic times for movement between stores. It is of course not run in actual time; the visitors' time stamps are estimated from an average walking pace of 3, 000 meters/hour, with random stops and "shopper interest profiles" programmable to let the visitors differ in activities, stores they visit, time spent in a specific type of store, etc. This application has not been tested with students yet but several test runs give promising results. 


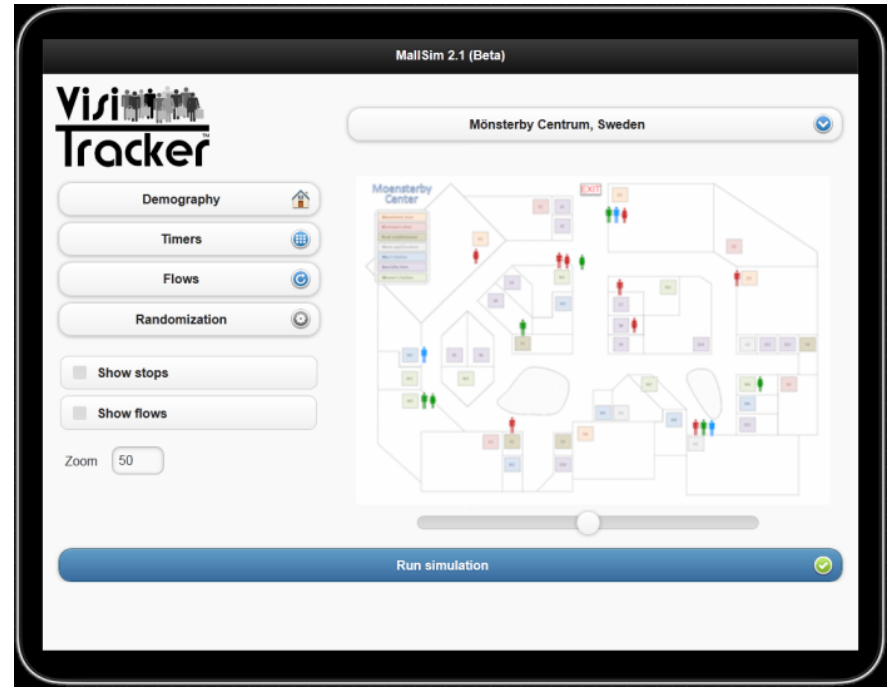

Fig. 12. The VisiTracker visitor flow simulator.

Besides the VisiTracker application (for shopping malls) we have also developed a similar application for exhibition malls (called FairTracker, www.fairtracker.se). The concept is more or less identical to gathering data at the shopping mall but we hope to get a different discussion (how QR codes and the data gathering can be integrated in e.g. marketing, sales and CRM modules in an ERP). FairTracker has not been tested with students yet; it will need more concept content before it is ready.

\section{The VisiTracker app}

Scanning QR codes is in itself a fully viable method for collecting data. We even believe our concepts could have commercial potential - but they do not render real-time data, to emulate what commercial offerings such as Path Intelligence [16] or Navizon offers. The second app developed for Android covers that gap (for demonstration purposes). It builds on the same services (ITS) as ARC Defense, but has as only purpose to register how many times there are devices detected in the grid.

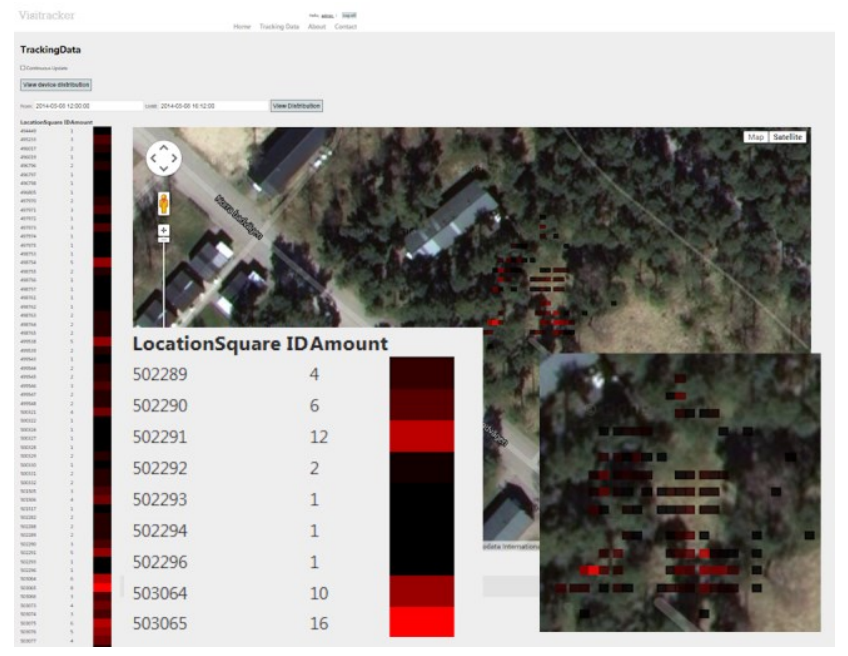

Fig. 13. Real-world VisiTracker data generated from mobile phone app. Left a "heatmap" of how many registrations that are made within a specific location square, to the right the same data displayed on top of a Google map of the area.
The data generated could be used for discussions on locating activities in the mall to generate additional traffic, for safety (where are emergency exits needed) or creating a model for store space rental differentiation. If many pass by, it is an attractive location which perhaps may be an argument for higher rent.

There are several perspectives on how real-time, locationbased mobile (but also user) data could be used for various analytical exercises and discussions. There is of course a long way to go before any of the datasets generated in our simple demos can aspire on belonging to "the Big Data league".

\section{RESULTS}

The website (with QR code scanning) seems to work well in getting the students to emerge in a fictional shopping mall world. Although QR codes haven't become everybody's use, there are indications that their use will remain, and increase, in years to come [39]. One reason may be that most smartphones now come equipped with readers. It is not something a user will have to download manually anymore.

Our applications are very simplistic in design and scope, but cannot handle, or for that matter generate, as much data as would be desirable for complete analysis. An ERP data import tool is also needed. They are however "a poor man's solution" and fulfil the aim of showing students the concepts and a possibility to analyze data they themselves have been part in creating.

Starting fall 2014, we will have a revamped curriculum for our ERP degree. As new courses are developed, we believe our concept exercises themselves also will be developed further.

\section{CONCLUSIONS}

The applications are very simple (both in scope and to use) but have, in our view, enabled students to get a better understanding of Data Mining in general, and the potential of Reality Mining specifically. In discussions on emerging interaction technologies, presentations with and demonstrations of the mobile phone as part of the SMILE acronym (E as in Environment) has also been useful. The applications as well as workshops building on them will require further refinement over time as mobile technology and ideas for services develop. They are however a first step in introducing concepts which often are difficult to demonstrate with standard ERP demo data.

As mentioned, the student data generated is not currently integrated in the university's course ERP system but data can be analyzed with e.g. QlikView ${ }^{\circledR}$ which is used for other ERP/BI exercises or through the simulator. A student session generates useful data but not "big" (in volume) data so added, fictional data points are needed. But from student comments there seem to be an added interest when using "own" data in the exercise.

Although field data is very limited (applied in a spring 2014 class so far), the demonstrations also raise awareness among students on their own/personal and constant transmission of data when at locations where such information can be gathered - which, at least in a modern society, is almost "everywhere". While data collection merely records device location and behavior, the discussion in most groups seemed to end up in addressing concerns for the individual, more than technology. 


\section{ACKNOWLEDGEMENTS}

The ITS (Indoor Triangulation System) used in the apps was provided free of charge for student projects by Navizon Inc. (www.navizon.com). We are grateful for the possibilities provided through this arrangement.

The student apps were developed by Rens Hoskens from Thomas More university college (Geel, Belgium) as a final project for completing a Bachelor's degree in Computer Science.

Product names and other trademarks referred to in this work are the property of the respective trademark holders.

\section{REFERENCES}

[1] H. Gardner et al., The HBR List: Breakthrough Ideas for 2006. Harvard Business Review 84, 2 (February 2006), pp. 35-67.

[2] N. Eagle and A. Pentland, Reality mining: sensing social complex systems. Personal Ubiquitous Computing 10 (2006), pp. 255-268. DOI 10.1007/s00779-005-0046-3.

[3] N. Eagle, D. Lazer, and S. Hanson, Inferring Friendship Network Structure by Using Mobile Phone Data. Proceedings of the National Academy of Sciences of the United States of America 106, 36 (09/2009), pp. 6955-6966. DOI 10.1073/pnas.0900282106.

[4] S. Datt, The Information Explosion: Trends in Technology 2011 review. Journal of Gov. Financial Management 60, 4 (Winter 2011), pp. 46-51, 3.

[5] B. Sheridan, A Trillion Points of Data. Newsweek (March 9, 2009), pp. 34-37. Download at http://hd.media.mit.edu/newsweek2 03.09.09.pdf.

[6] S. Baik, Rethinking QR code: analog portal to a digital world. Multimedia Tools and Applications 58, 2 (May 2012), pp. 427-434. DOI 10.1007/s11042-010-0686-9.

[7] T. Svane, Get your students to SMILE! Exploring emerging interaction technologies. IEEE ITHET 2013 (Antalya, Turkey), pp. 1-6. DOI 10.1109/ITHET.2013.6671064.

[8] T. Keerthi, A. K. Bandara, B. A. Price, and B. Nuseibeh, Distilling Privacy Requirements for Mobile Applications. ACM ICSE'14 (Hyderabad, India), pp. 871-882. DOI 10.1145/2568225.2568240.

[9] N. Moorodian, The importance of privacy revisited. Ethics in Information Technology 11 (2009), pp. 163-174. DOI 10.1007/s10676-009-9201-2.

[10] C. Huff and A. Furchert, Computing Ethics: Toward a Pedagogy of Ethical Practice. Communications of the ACM 57, 7 (July 2014), pp. 2527. DOI 10.1145/2618103.

[11] H. Yun, D. Han, and C. C. Lee, Understanding the use of location-based service applications: do privacy concerns matter? Journal of Electronic Commerce Research 14, 3 (August 2013), pp. 215-230.

[12] B. Liu, J. Lin, and N. Sadeh, Reconciling Mobile App Privacy and Usability on Smartphones: Could User Privacy Profiles Help? ACM WWW '14 (Seoul, South Korea), pp. 201-211. DOI 10.1145/2566486.2568035.

[13] M. Gil, P. Giner, and V. Pelechano, Personalization for unobtrusive service interaction. Personal Ubiquitous Computing 16 (2012), pp. 543-561. DOI 10. 1007/s00779-011-0414-0.

[14] C-W You et al., Using Mobile Phones to Monitor Shopping Time at Physical Stores. Pervasive Computing 10, 2 (April-June 2011), pp. 37-43. DOI 10.1109/MPRV.2011.14

[15] A. Galati and C. Greenhalgh, Human Mobility in Shopping Mall Environments. ACM MobiOpp'10 (Pisa, Italy), pp. 1-7. DOI $10.1145 / 1755743.1755745$.

[16] A video from Path Intelligence explaining their concept can be viewed at https://www.youtube.com/watch?v=_20JRTgTxbE. Further information can be found on their website http://www.pathintelligence.com.

[17] B. Ausmeier, T. Campbell, and S. Berman, Indoor Navigation Using a Mobile Phone. IEEE ACSEAC 2012 (Gaborone, Botswana), pp. 109115. DOI 10.1109/ACSEAC.2012.26.

[18] T. Yuichiro and M. Sugimoto, A user-adaptive city guide system with an unobtrusive navigation interface. Personal and Ubiquitous Computing 13, 2 (February 2009), pp. 119-132. DOI 10.1007/s00779-007-0192-x.
[19] J. Valentino-DeVries and J. Angwin, Latest Treasure Is Location Data; As Lawmakers Ready Hearings, Insurers, Car Makers, Even Shopping Malls Seek to Track Customers. Wall Street Journal (online) May 11, 2011. Can be read/downloaded from http://online.wsj.com/news/articles/ SB10001424052748703730804576313522337383898.

[20] E. Martin et al., Precise Indoor Localization Using Smart Phones. ACM MM'10 (Firenze, Italy), pp. 787-790. DOI 10.9999/9999999.9999999. R at http://www.icsi.berkeley.edu/pubs/speech/preciseindoor10.pdf

[21] C. Berberis et al., Experiencing Indoor Navigation on Mobile Devices. IEEE IT Professional 16, 1 (January - February 2014), pp. 50-57. DOI 10.1109/MITP.2013.54

[22] K. Arning et al., Insights into user experiences and acceptance of mobile indoor navigation devices. ACM MUM'12 (Ulm, Germany), Article 41, pp. 1-10. DOI 10.1145/2406367.2406417.

[23] A. Pentland, Wearable Information Devices. IEEE Micro 21, 3, pp. 12-15. DOI 10.1109/MM.2001.928761.

[24] S. A. Hoseini-Tabatabaei, A. Ghulak, and R. Tafazolli, A Survey on Smartphone-Based Systems for Opportunistic User Context Recognition. ACM Computing Surveys 45, 3: Article 27 (June 2013), pp. 27:127:51. DOI 10.1145/2480741.2480744.

[25] L. Shaul and D. Tauber, Critical success factors in enterprise resource planning systems: Review of the last decade. ACM Computing Surveys 45, 4 (August 2013), pp. 55:1 - 55:39. DOI 10.1145/2501654.2501669.

[26] R. Chiang, P. Goes, and E. Stohr, Business Intelligence and Analytics Education, and Program Development: A Unique Opportunity for the Information Systems Discipline. ACM Trans. Manage. Inf. Sys. 3, 3 (October 2012), Article 12. DOI 10.1145/2361256.2361257.

[27] M. Hepner and W. Dickson, The Value of ERP Curriculum Integration: Perspectives from the Research. Journal of Information Systems Education 24, 4 (Winter 2013), pp. 309-326.

[28] P. Nastase and D. Stoica, A New Business Dimension - Business Analytics. Accounting and Management Information Systems 9, 4 (December 2010), pp. 603-618.

[29] Ericsson Mobility Report, June 2014. The full report (as pdf) can be downloaded at http://www.ericsson.com/mobility-report.

[30] M. Endler, Cisco Brings Location-Based Big Data To Shopping. InformationWeek (online) November 15, 2012, pp. 1-2. Can be accessed at http://www.informationweek.com/big-data/big-data-analytics/ciscobrings-location-based-big-data-to-shopping/d/d-id/1107407.

[31] C. Leyh, Teaching ERP systems: Results of a survey at researchoriented universities and universities of applied sciences in Germany. Journal of Information Systems Education 23, 2 (July 2012), pp. 217-227.

[32] T. P. Cronan and D. E. Douglas, A Student ERP Simulation Game: A Longitudinal Study. The Journal of Computer Information Systems 53, 1 (Fall 2012), pp. 3-13.

[33] G. Joseph and A. George, ERP, learning communities, and curriculum integration. Journal of Information Systems Education 13, 1 (April 2002), pp. 51-58.

[34] T. Johnson et al., A Customized ERP/SAP Model for Business Curriculum Integration. Journal of Information Systems Education 15, 3 (Fall 2004), pp. 245-253.

[35] F. Wu, Discussion on Experimental Teaching of Data Warehouse \& Data Mining Course for Undergraduate Education. ICCSE 2012 (Melbourne, Australia), pp. 1425-1429. DOI 10.1109/ICCSE.2012.6295331.

[36] S. J. Vaughan-Nichols, Will Mobile Computing's Future Be Location, Location, Location? Computer 42, 2 (February 2009), pp. 14-17. DOI 10.1109/MC.2009.65.

[37] S-C. Ho, W-Y. Sun, and Y-M. Wang, Investigation of Factors Influencing the Adoption of Mobile Data Services. In Proceedings of ACM ICEC 2011 (Liverpool, U.K.). DOI 10.1145/2378104.2378115.

[38] E-S. Lohan et al., End-User Attitudes towards Location-Based Services and Future Mobile Wireless Devices: The Students' Perspective. Information 2, 3, pp. 426-454. DOI 10.3390/info2030426.

[39] B. Sago, Quick Response (QR) Codes in Marketing: The Relationship Between Consumer Interest and Likelihood of Future Use. International Journal on GSTF Business Review 1, 3 (January 2012), pp. 167-172. DOI 10.5176/2010-4804_1.3.112. 